\title{
Cumulative disparities in the dynamics of working poverty for later-career U.S. workers (2002-2012)
}

Jo Mhairi Hale I jo.hale@st-andrews.ac.uk Christian Dudel I dudel@demogr.mpg.de Angelo Lorenti I lorenti@demogr.mpg.de 
Cumulative disparities in the dynamics of working poverty

for later-career U.S. workers (2002-2012)

Jo Mhairi Hale ${ }^{1,2}$, Christian Dudel ${ }^{2}$, and Angelo Lorenti ${ }^{2}$

${ }^{1}$ University of St Andrews, Fife, Scotland

${ }^{2}$ Max Planck Institute for Demographic Research. Rostock, Germany

Corresponding author:

Dr. Jo Mhairi Hale

School of Geography \& Sustainable Development

Irvine Building

North St

St Andrews

Fife

Scotland

KY16 9AL

Tel. $+44(0) 7548631627$

Email Jo.Hale@st-andrews.ac.uk 


\begin{abstract}
Many more Americans experience working poverty than unemployed poverty, a situation which was only exacerbated by the Great Recession. The consequences of working poverty for later-career workers - who should be in their highest-earning ages - are particularly dire. We expect that later-career workers are especially vulnerable in terms of risk and duration of working poverty and that those who have accumulated disadvantages over their life courses, in terms of the intersecting dimensions of race/ethnicity, gender, early-life socioeconomic status, and educational attainment, will suffer disproportionately. We use incidence-based Markov chain multistate models to analyze the U.S. Health and Retirement Study, which is representative of the U.S. population aged 50 and older. We find that Black women and men, Latinx, those who experienced more earlylife disadvantages, and people with lower education have higher risk and longer durations in working poverty over the period 2002-2012. Our findings also suggest that when confronted with economic hardship - the Great Recession - later-career workers who originate in lower socioeconomic statuses, especially Blacks and Latinx, are in more precarious economic positions. Important from a policy perspective, educational attainment only partially mediates the association between race/ethnicity and working poverty; disparities persist.
\end{abstract}

Keywords: Poverty, Work, Aging, Life Course, Cumulative Disadvantage, Great Recession 


\section{Introduction}

Even using a conservative measure of poverty, the U.S. Census Bureau estimated 39.7 million people (about 12.3\% of the U.S. population) were poor in 2017 (Fontenot et al. 2018). The majority of these families have at least one adult employed, i.e., "the working poor" (Danziger et al. 2012). One driver of working poverty is that in the U.S., as well as in other higher-income countries, there have been dramatic shifts in the shape of the labor market over the last decades, including in types of jobs and the demographic profile of the working population. Much of U.S. employment growth has been in service occupations, which are characterized by low wages, variability in hours, few to no benefits, low unionization rates, and job precarity (Autor et al. 2013; Farber 2008; Finnigan and Hale 2018; Halpin 2015; Kalleberg et al. 2000). The composition of the working population has also changed, with increased shares of women, ethnic minorities, and older workers (Toossi 2002).

Older workers constitute an especially vulnerable group in the U.S. labor market, partly due to skills mismatch, age discrimination, worse health status inhibiting work opportunities, and the long-lasting impact of the Great Recession (Autor et al. 2013; Engemann and Wall 2009; Rehkopf et al. 2017). Older individuals from disadvantaged backgrounds have been hit especially hard by the recession in terms of access to employment (Dudel and Myrskylä 2017). However, it is unknown to what extent disadvantaged older workers have experienced increasing vulnerability to lower earnings and working poverty, as has been the case for their younger counterparts (Desmond and Gershenson 2016; Keys and Danziger 2008; Li et al. 2019). These vulnerabilities are particularly important for later-career workers as we would expect them to be at the peak of their earning potential. Losing those years of higher earnings will affect them not only in the moment, but for their future Social Security earnings and retirement savings. Furthermore, this population is 
growing because of the unprecedentedly-large Baby Boomer cohort anticipating unprecedentedlylong life expectancies.

We engage with the question of understanding later-career workers' experiences of working poverty from the vantage point of cumulative inequality, intersectionality, and life course theory, predicting that social positionalities over the life course intersect to affect life outcomes (Browne and Misra 2003; Cho et al. 2013; Collins 2015; Schafer et al. 2011, 2013). Read together, we can derive from these theories that those who experience multiple disadvantages over their life courses (racial/ethnic and early-life socioeconomic disadvantage and lower educational attainment) will have higher risk than their more privileged peers of experiencing working poverty and also a longer share of lifetime spent in working poverty. We also hypothesize that a lack of familial wealth and low human/social capital places people who originate in lower socioeconomic statuses (SES), especially Blacks and Latinx (Bloome 2014; Conley 1999; Neckerman and Torche 2007; Western et al. 2012), in more precarious positions when disaster strikes, such as during a macroeconomic shock - in this study, the Great Recession. This will likely also be the case for the COVID-19 Recession.

The goal of this study is to assess the burden of working poverty for those who have disadvantaged origins. That is, we aim to describe trends and disparities in working poverty, and we do not try to model all potential mechanisms behind these disparities. We estimate disparities in risk and expectancies by race/ethnicity, gender, and exposure to early-life disadvantages, as well as their intersections. To assess how the Great Recession put disadvantaged workers at further disadvantage, we calculate lifetime risk of and expectancies in working poverty in the years leading up to the financial crisis (2002-2007) and during the recession (2008-2012). Moreover, we provide 
counterfactual estimates indicating to what extent race/ethnicity's association with later-career working poverty is mediated through educational attainment and labor force experience.

We use data from the Health and Retirement Study, a longitudinal survey representative of the United States population age 50 and older. We apply discrete-time survival analysis and multistate models to calculate two key indicators of working poverty: the lifetime risk at age 50 of ever experiencing working poverty and the expected remaining lifetime at age 50 spent in working poverty. These indicators allow us to summarize dynamic labor market trajectories, which might consist of several episodes of working poverty for some individuals and none for others, while showing how disadvantage accumulates (Hayward and Lichter 1998; Lorenti et al. 2019). Overall, our findings show distinct disparities in both risk of and expectancies in working poverty, with early-life disadvantaged Blacks and Latinx facing the highest risk and longest expectancies. Furthermore, when confronted with economic hardship (e.g., the Great Recession), disadvantages intersect to place those multiply disadvantaged in even more precarious economic positions.

This paper contributes to the literature in several ways. First, we study how accumulated life course disadvantages are associated with experiences of working poverty for a particularly vulnerable population - later-career US workers - in the context of the Great Recession. Second, our findings highlight the importance of going beyond access to employment to also consider economic returns to employment when assessing disparities. Third, our analysis shows the usefulness of our two key indicators - the risk of experiencing working poverty and life expectancy spent in working poverty. Fourth, our counterfactual analysis shows how intervening on education would affect disparities between groups, and, to some extent, it allows us to disentangle pathways through which inequalities accumulate. 


\section{Background}

This project draws on three large bodies of literature: poverty, social (im)mobility, and life course studies. As to the first, in the U.S., during the period of analysis, there were four times more people in working poverty than in poor households where no one is working (Brady et al. 2010). Second, decades of social mobility research tells us that individuals are likely to mirror their parents' educational, occupational, and socioeconomic attainment, resulting in the intergenerational transmission of poverty (Becker and Tomes 1994; Blau and Duncan 1967; DiPrete 2002; Hout and DiPrete 2006; Sewell et al. 1970). Third, key characteristics, both ascribed (race/ethnicity, gender, familial SES) and achieved (educational attainment) interact over the life course to affect life outcomes (Collins 2015; Crenshaw 1994; Killewald and Bryan 2018; Montez and Hayward 2014; Schafer et al. 2011). Life course theory is also relevant in that life course stage influences risk of working poverty (e.g., transitions into or out of partnership (Van Winkle and Struffolino 2018)), as well as vulnerability to macroeconomic shock (Elder Jr. 1998). For example, in the wake of the Great Recession, older displaced workers experienced the largest earnings' declines, with a lower probability than younger workers of being rehired in the years since (Farber 2011). The empirical research based on these three literatures ranges from individual-level analyses of predictors of poverty spells to cross-national studies of how the Great Recession affected the labor force. We focus on their juncture: measuring working poverty for later-career workers from different social backgrounds before and during the Great Recession.

\section{Working Poverty}

Since the 1970s, the large body of work on the dynamics of poverty has expanded. One of the key turning points in understanding poverty was the finding that most poverty spells are relatively short and that most people who experience poverty spells are not chronically poor, despite the 
collective imaginary of deep and chronic poverty (Bane and Ellwood 1986; Magnuson and VotrubaDrzal 2009; Stevens 1994, 2012). This evidence that affirmed the wide scope of the poverty problem spurred a glut of work attempting to identify individual, cultural, or structural predictors of poverty (Brady et al. 2017; Desmond and Western 2018; Jargowsky 1997; Julius 1987). Much of this work has focused on understanding risk factors for spells of poverty, e.g., birth, divorce, job loss (McKernan and Ratcliffe 2005), predictors of the persistence of poverty—what makes some individuals repeatedly or chronically poor? (Hoynes et al. 2006; Lichter and Crowley 2002), and the intergenerational transmission of poverty, closely linked with research on social mobility, cumulative disadvantage, and life course studies more generally (Blau and Duncan 1967; Dewilde 2003; DiPrete and Eirich 2006; Mayer 2009; Schafer et al. 2011; Sewell et al. 1970).

As for the working poor specifically, in the U.S., the working poor represent an increasing share of the population - a $25 \%$ growth from 2000 to 2010 - and thus are almost a hallmark of the Great Recession era (Brady et al. 2010; Thiede et al. 2018). Research thus far has established a sociodemographic profile of the middle-aged (aged 51-61) working poor in the late nineties and early 2000s; however, since then, there have been significant shifts in the labor market (Lee et al. 2005). This profile also does not address early-life factors that we know from social mobility research are associated with risk, such as parents' education or SES, instead focusing on contemporary predictors, e.g., marital status, similar to other recent work (Van Winkle and Struffolino 2018).

There is also a large body of literature measuring the impact of Earned Income Tax Credit (EITC), which originally began in 1975 and was intended to benefit low-income, working families. Its expansion over the last forty years and state-level variation in implementation have permitted analyses determining the efficacy of the program in alleviating some of the burden of working 
poverty (e.g., Pilkauskas and Michelmore 2019). Nevertheless, better understanding the life course origins of working poverty remains an important task, as EITC is, at best, an efficacious intervention and at worst, a band-aid on a gaping wound.

The literature also tends to focus on risk of poverty versus life expectancies in working poverty (Thiede et al. 2015, 2018; Thiede and Kim 2015). To this last, although identifying risk (via incidence or prevalence) is an important first step in understanding working poverty, poverty's cyclical nature means that estimating expectancies in working poverty can contribute insight into the burden of working poverty. How much of their later career do individuals spend in working poverty? And how do race/ethnicity, gender, early-SES, and education intersect to generate and perpetuate disparities in the burden of working poverty? Expectancies often reveal a more nuanced assessment of the effects of cumulative disadvantage (Hayward and Lichter 1998), thus expectancies are important for measuring inequalities (Dudel and Myrskylä 2017). Another contribution of this study is that the literature on labor market expectancies has not, thus far, distinguished between labor force participation and economic returns to employment.

\section{Later-career workers and the Great Recession}

Although it is common for research on labor force dynamics to focus on the prime workingage population, we argue that workers who are in the latter-stages of their careers and who should be at peak earnings are a particularly vulnerable group. This is partially related to the shifting terrain of post-industrial employment, including the insecure "gig economy." Even prior to the recession, the skills mismatch of later-career workers in this new economy contributed to unprecedented job churning in the private sector for older males (Autor et al. 2013; Farber 2008, 2010). In the immediate aftermath of the recession, Engemann and Wall (2009) found increases in employment for age $55+$ workers, but hypothesize that the reasons are negative, i.e., reluctance to leave the labor 
market because of retirement savings losses or related concerns. However, other research suggests that previously full-time workers who lost jobs in the Great Recession suffered significant declines in earnings and encountered lower re-employment rates - many turning to part-time employment (Farber 2011). In sum, later-career workers appear to be especially vulnerable participants in the current labor market and in the wake of the Great Recession (with potential implications for the COVID-19 Recession), but results remain inconclusive as to working poverty.

Furthermore, we can expect that the vulnerability of the age 50 and older population is heterogenous. Other factors that affected the impact of the Great Recession on older U.S. residents' employment trajectories include race/ethnicity, gender, early-SES, and educational attainment. For example, during the recessionary years of 2008 to 2011, Latinos experienced the largest decline in years of working life expectancy (WLE), and Black men declined precipitously in relative WLE, from spending 57.3\% of their age 50+ lives working to only 47.7\% (Dudel and Myrskylä 2017). In general, men's relative WLE decreased by more than women's in the recessionary years (Dudel and Myrskylä 2017). Childhood SES likewise impacts length of working life for those age 50+, with women and men who had more disadvantaged childhoods working for substantially less of their remaining lives and spending more time in disability compared to those from more advantaged families (Lorenti et al. 2020).

Predictably, educational attainment is important, interacting with race/ethnicity, gender, and early SES to impact WLE and decline in WLE after the economic crash (Dudel and Myrskylä 2017; Lorenti et al. 2020). Educational attainment also moderates the association between the Great Recession and income. Those with only a high school diploma faced a much larger decline in earnings subsequent to the 2008 market crash than those with a college degree (Struffolino and Van Winkle 2019). In sum, findings suggest that how the recession impacted U.S. workers is dependent 
upon age, race/ethnicity, gender, early-SES, and educational attainment. This leads us to hypothesize that the Great Recession likely also increased risk of and expectancies in working poverty most for vulnerable subpopulations.

Hypotheses

Based on these theoretical considerations and empirical findings, we make three predictions: First, later-career workers who experience life-course disadvantages, including by race/ethnicity, gender, childhood disadvantage, and educational attainment, will have higher risk of and longer expectancies in working poverty. Second, the Great Recession will be more detrimental for latercareer workers who experience life-course disadvantages, including racial/ethnic (Black or Latinx v. White), gender (women v. men), childhood disadvantage (more v. less), and educational attainment (less v. more). And third, as educational attainment is a major mediator linking race/ethnicity and later-life working poverty, we predict that intervening on education will partially disrupt the association between race/ethnicity and risk of and expectancies in working poverty.

\section{Data and Methods}

Data and measurement

We use the U.S. Health and Retirement Study (HRS), a nationally-representative, populationbased, biennial panel survey of Americans aged 50 and older and their spouses of any age. The University of Michigan conducts the HRS, which is funded by the National Institute on Aging (grant number NIA U01AG009740) and the U.S. Social Security Administration (University of Michigan 2017). The data can be obtained at no cost after registration online: http://hrsonline.isr.umich.edu/. We use the harmonized data files from RAND Version P (RAND Center for the Study of Aging 2017). 
We include individuals aged 50 to 69 during the years 2002 to 2012 in our analysis. We focus on this age range for several reasons. At the lower bound, we focus on workers age 50 and older because they should be in their prime-earning ages; earnings at these ages will significantly impact health, pensions, social security, and other retirement savings. At the upper bound, we set maximum age at 69 because using a younger age, e.g., the statutory retirement age, may miss non-standard trajectories into retirement, such as phased retirement, labor market reentries (most labor market reentries happen shortly after first retirement) (Hayward et al. 1994), and postponed retirement (Cahill et al. 2015; Pleau and Shauman 2013). We must be attentive to these non-standard patterns because they are more prevalent for women, Blacks, and Latinx, and therefore important for our analyses (Calvo et al. 2017). Finally, though retirement after statutory retirement age is nonnegligible (Calvo et al. 2017), beyond age 69, labor force participation is rather low (Dudel and Myrskylä 2020; Warner et al. 2010).

We focus on the years 2002 to 2012 for three main reasons. First, having a balance of years before the onset of the Great Recession (2002-2007) and during/since (2008-2012) means our estimates of working life expectancy across the two eras are more equivalent, each drawing on five to six years of data. Second, wave 6 of the HRS (conducted primarily in 2002) marks the first wave at which RAND constructed a household-adjusted measure for whether respondents were below the official poverty threshold (details below). And third, over time the impact of the recession attenuated, so including years after 2012 may dilute the distinction between the pre- and recessionary period. Our final sample after restricting to age 50 to 69 , years 2002 to 2012 , and using listwise deletion for missingness is 18,374 individuals, for whom we analyze 59,561 person-waves.

Work and working poverty. We define individuals as working if they self-report working fulltime or part-time (but not being unemployed), and if they report working at least 27 weeks of the 
previous year". For those who meet the definition of working, we count as "poor" those whose household income is below $200 \%{ }^{2}$ of the official Federal Poverty Line (FPL). ${ }^{3}$ We use the poverty threshold variable constructed by RAND, which uses the Bureau of Labor Statistics definition of the poverty threshold, including adjusting for household composition (RAND Center for the Study of Aging 2017). We also factor in RAND's household wealth variable that includes before-tax income from earnings, unemployment, social security, social security insurance, pensions, but not non-cash benefits or capital gains. We average this wealth measure over the entire study period and then divide it into quintiles. As this study is focused on the "working poor," we exclude from working poor those respondents whose average wealth over their entire study participation places them in the upper two quintiles of the wealth distribution. ${ }^{4}$ We exclude those who have accumulated significant economic resources on which to draw because over this age range of 50-69, partiallyretiring individuals may choose to work, e.g., for health insurance, supplementary income, or to stay engaged outside the home. This type of worker should not be classified "working poor" despite low wages.

Predictors. Age is measured in completed years. We create categorical variables for gender (women or men) and race/ethnicity (non-Hispanic White, Black, and non-Black Latinx, henceforth

\footnotetext{
${ }^{1}$ Taking into consideration results from Thiede et al.'s (2015) analysis, in alternative analyses, we define working poor as below, but not restricted by reports of hours or weeks worked. We also restrict to those who report averaging at least 17 hours/week. Results are consistent.

${ }^{2}$ We also examine those $150 \%$ above the FPL and results are qualitatively consistent; see Figure 1 for an example.

${ }^{3}$ We use $200 \%$ of the FPL and not the FPL itself because the FPL is widely considered an inaccurate measure of hardship. The FPL relies on an approach conceived in the 1960s, discussed at length elsewhere (Brady 2003; Cellini et al. 2008; Meyer and Sullivan 2012; Thiede et al. 2015). As an example of the degree to which the FPL is an underestimate of poverty, in 2014 , the FPL for a family of four $(\$ 24,008)$ was approximately one-third the median income level (Bernstein et al. 2018).

${ }^{4}$ This approach may misidentify some working poor as non-poor and smooth over some of the Great Recession's negative effect on wealth. However, there is little movement from the top two quintiles into lower quintiles when examining transitions across wave.
} 
White, Black, Latinx ${ }^{5}$ ). If an individual self-reports three or more of the following, we consider them low early-life SES: low childhood SES, poor childhood health, parents' education less than $8^{\text {th }}$ grade, father did not contribute economically (unemployed, absent, dead), father's lower-status occupation, childhood family moved due to financial hardship, and/or childhood family borrowed money due to financial hardship. We distinguish four levels of educational attainment: less than high school/general equivalency degree (GED), high school diploma, some college, or college and higher. ${ }^{6}$ We define the pre-recession period as 2002-2007 and 2008-2012 as recessionary.

Analytic Strategy: Multistate modeling

To calculate the incidence of working poverty during ages 50 to 69 and remaining working life spent in working poverty, we use a multistate approach (Dudel and Myrskylä 2017; Hoem 1977; Skoog and Ciecka 2010). The multistate approach allows us to model transitions between labor force states and is based on the probabilities of transitioning from one state to another, e.g., the probability of moving from full-time, non-poor employment to working poverty. Many useful quantities can be calculated from these transition probabilities, including their population-level implications, e.g., the probability of ever experiencing working poverty and average number of years individuals will spend in working poverty. This makes inequalities and disparities between groups measurable in a straightforward way, as well as allowing us to show the accumulation of (dis)advantage (Hayward and Lichter 1998).

We use a multistate model with four states: non-poor employment (full time or part time); working poverty; unemployment; and one category capturing retirement, disability, or otherwise

\footnotetext{
${ }^{5}$ Due to issues with sample size, all self-identified Hispanic/Latinx are categorized as one group despite clearly being a heterogeneous population. Unfortunately, further distinction between native-born and foreign-born and, for the latter, by country of origin is not possible.

${ }^{6}$ For the earlier cohorts under study, relatively few respondents have higher education, especially by racial/ethnic subgroups, so further distinction is not feasible.
} 
not being in the labor force. In addition to transitions between labor force states the model also captures mortality. To estimate the transition probabilities between states we use discrete event history analysis (Allison 1982). Transition probabilities depend on previously-described predictors. We estimate models separately for men and women, thus implicitly interacting all predictors with gender. This allows us, for instance, to compare remaining expectancies in working poverty for Latinas versus White women before and during the recession. We do so with two sets of models: one set in which only one explanatory variable is included, for instance race/ethnicity, and one set of models that includes all variables. The former are used to predict outcomes by single variables, while the latter are used to model the intersections between all variables. In all models, age is included as a smoothing spline (Yee 2010), while other variables are included as sets of dummy variables.

The multistate approach requires us to specify a starting distribution of each of the labor force states at age 50 . We estimate this from the data based on individuals aged 45 to 54 to achieve a larger sample size, and separately for each group for whom we present results, e.g., we estimate this distribution for Latinas with low early-life SES, etc. To calculate standard errors and confidence intervals we use a bootstrap approach (Cameron and Trivedi 2005). The results presented below are based on analyses not including the sampling weights; however, results with weights are similar. All code is available online.

Counterfactual analysis: The mediating effect of education

When studying the association between early-life factors and outcomes later in life, intermediate confounding becomes particularly problematic. Race/ethnicity is associated with early-life disadvantage, which affects educational attainment, and all three directly and indirectly affect labor force participation. To determine to what extent an intervention on educational 
attainment could disrupt the link between race/ethnicity and later-life working poverty, we use a counterfactual framework. This method is particularly useful because we can simultaneously reduce bias from intermediate confounding and test an intervention scenario (Nandi et al. 2012; VanderWeele 2015; VanderWeele and Robinson 2015).

In brief, we block the pathways from race/ethnicity to work outcomes that go through educational attainment (Gran et al. 2015). We calculate expectancies in working poverty as if the distribution of educational attainment does not differ by race/ethnicity while keeping early-SES constant, i.e., as if the proportion of individuals with less than a high school degree is the same for individuals with low and high early-SES irrespective of race/ethnicity. The distribution of educational attainment is taken from the White population. Outcomes by educational attainment still differ by race/ethnicity and between the low and high early-SES group. For example, Black individuals with low early-SES and less than a high school degree might have a lower working life expectancy than White individuals with low early-SES and less than a high school degree. Thus, even in the counterfactual scenario expectancies in working poverty can differ, but these differences are only due to different payoffs of education, and not to the different likelihood of attaining higher education.

The procedure involves several steps. First, we calculated lifetime spent in working poverty by all combinations of race/ethnicity, early-SES, and education. Second, we combined and aggregated these estimates to estimates only by race/ethnicity, by weighting the educational categories according to the distribution of Whites' educational attainment. This was done for both low and high early-SES, which then were also combined in the weighting step. Performing these steps provides estimates of the lifetime spent in working poverty where differences between racial/ethnic groups are solely due to differences in early-SES and in the payoff of education. 
Compared to the actual findings, the counterfactual scenario shows to what extent intervening on education would reduce disparities between groups if potential disadvantage through low earlySES and differential returns to education remain.

\section{Results}

Descriptive results

Table 1 shows the sample size in total and for different groups, as well as the number and percentage of transitions among labor force states, and the percentage of transitions specifically from and to working poverty. The number of transitions is important as for discrete event history analysis the measurement is of individual transitions between waves of the HRS. Overall, our analyses are based on working trajectories of close to 19,000 individuals and approximately 60,000 transitions. There are more women than men in the sample, which is expected in a sample of older individuals. The sample sizes for Blacks and Latinx are much smaller than for Whites, and the majority of the sample has less than a college or university degree. The sample is relatively balanced with respect to childhood SES.

Table 1 about here

Also shown in Table 1 is the proportion of transitions of each group which starts or ends in working poverty. This already shows considerable differences between groups. For instance, Latinx are six times more likely than Whites to experience a transition from or to working poverty, while Blacks are five times more likely. Those with lower educational attainment and lower early-SES have more transitions into working poverty than their higher-educated, more advantaged counterparts.

Figure 1 about here 
Figure 1 shows unadjusted trends over time in working poverty using $200 \%$ of the poverty line as poverty threshold (our main outcome; solid line); trends in working poverty using 150\% of the poverty line as threshold (dashed line); and trends in self-reported unemployment (dotted line). All three measures show a clear rise in prevalence at the time of the recession for those aged 50-69. Moreover, while before 2010 all three measures show a similar trend, the following period exhibits the opposite pattern between working poverty and unemployment, suggesting that individuals escaping unemployment may have transitioned to working poverty. These findings also indicate that differences between results when using different definitions of working poverty are mostly in levels, and neither in trends nor in differences between groups.

Risk of and expectancies in working poverty

Working life expectancy (WLE) is clearly embedded in partial life expectancy (PLE) - the total lifetime individuals live during the age interval from 50 to 69 - in that WLE is a share of PLE. The multistate approach provides us with estimates of PLE (Appendix 1 Table 4). The disparities in PLE we find are in line with the literature, e.g., women live longer than men; Latinx live longer than Whites, who live longer than Blacks; the higher educated live longer than the lower educated; and for most groups (except Latinx ${ }^{7}$ ), more early-life disadvantage is associated with lower PLE (Lariscy et al. 2015, 2016; Meara et al. 2008).

To test Hypothesis 1 that later-career individuals who have life course disadvantages will experience higher risk of and longer expectancies in working poverty than their more advantaged counterparts, we estimate risk of and expectancies in working poverty by race/ethnicity, gender,

\footnotetext{
7 That Latinx with more early-life disadvantage have longer partial life expectancy is likely related to the migrant health advantage. Migrants are likely to have parents with lower educational and occupational attainment and have experienced more financial hardship; however, Latinx migrants to the US experience longer life expectancy-the "Hispanic Health Paradox" (Riosmena et al. 2017).
} 
early-disadvantage, and education. We report results separately for each variable in Figure 2 Panel A (risks) and Panel B (expectancies), and we provide estimates combining all variables in Table 2 (expectancies only). Expectancies in states other than working poverty (Working full-/part-time, unemployment, not in the labor force, partial life expectancy) are provided in the appendix.

Figure 2 about here

Gender: Women generally have higher risk and spend more time in working poverty than men, although the differences are not substantial (Figure 2). This is true for the total population's risk of (women 33\%, 95\% CI: 31\%, 35\%; men 30\%, 95\% CI: 28\%, 32\%) and expectancies in working poverty (men's years $1.195 \% \mathrm{CI}$ : 1.0, 1.2; women's years $1.2,95 \% \mathrm{CI}: 1.1,1.3$ ), as well as for most bivariate combinations of gender and the other variables.

Race/ethnicity: Racial/ethnic disparities in risk and expectancies are marked. Latinos, on average, have approximately 50 percentage points (pp) higher risk and spend three years longer in working poverty than White men (Table 2). Black men also have substantially higher risk than White men (Black 43\%, 95\% CI: 38\%, 47\%; White 15\%, 95\% CI: 13\%, 17\%) and spend more than one additional year in working poverty (Table 2). Compared to Latinos, Black men spend more time out of the labor market (e.g., unemployed), so their relative advantage in terms of working poverty may not be reflective of actual labor market advantage (Appendix 1 Table 4). Racial/ethnic disparities for women are qualitatively similar to their men counterparts in that Blacks and Latinas experience higher risk of and longer expectancies in working poverty. However, the difference between Latinas and Black women is less pronounced in risk (Latinas risk 58\%, 95\% CI: 53\%, 63\%; Black risk 50\%, 95\% CI: 46\%, 54\%) and expectancies (Table 2).

Early-life SES: Disparities between high and low early-life SES, as shown in Figure 2, are also as expected. Individuals with a low SES during early-life have higher risk of working poverty 
and can expect to spend more years in working poverty than individuals with a high early-life SES. For men, those with lower early-SES have almost double the percent risk (41\% vs. 21\%) and for women the socioeconomic disparity is almost as wide (41\% vs. $25 \%)$.

Educational attainment: As hypothesized, educational disparities are substantial, and those who have less education have higher risk and can expect to spend longer in working poverty than their higher-educated counterparts (Figure 2, Table 2). The largest difference is between those who have less than a high school degree and those who have a high school diploma; the gains from further education beyond a high school diploma are less pronounced (Table 2). For example, those with less than high school have 28 percentage points higher risk of working poverty compared to those with a high school diploma (<HS 56\%, 95\% CI: 52\%, 61\%; HS 28\%, 95\% CI: 25\%, 31\%), whereas the jump from high school diploma to college or higher is 17 percentage points (College $11 \%, 95 \% \mathrm{CI}: 8 \%, 13 \%)$. Although the emphasis here is on working poverty, it is worth noting that White men and women with the highest education spend more time in unemployment than working poverty (Appendix 1 Table 4).

Intersections: Thus far we have focused primarily on bivariate associations, only disaggregating by gender. While the sample sizes are inadequate to test all predictors together, we now present examples of how the accumulation of disadvantages also affect risk and expectancies in working poverty. While women on the whole have higher risk of and longer expectancies in working poverty, Latinas have lower risk (women 58\%, 95\% CI: 53\%, 62\%; men 67\%, 95\% CI: $62 \%, 72 \%$ ) and spend considerably less time in working poverty than their men counterparts (women 2.7 years 95\% CI 2.3, 3.0; men 3.4 years 95\% CI 3.0, 3.9). This demonstrates that gender operates differently depending on race/ethnicity. 
Racial/ethnic disparities persist regardless of early-life SES and educational attainment, although the extent of the disparities depend on other positionalities (Table 2). We do not find a consistent pattern in time spent in working poverty based on how race/ethnicity intersects with early-life disadvantage (Table 2). The widest disparity is for Latinos, where the difference is about one year longer in working poverty for the more disadvantaged, regardless of subsequent educational attainment. White men have the narrowest disparity in time spent in working poverty by early disadvantage, regardless of educational attainment. However, the racial/ethnic disparities continue to dominate: early-advantaged Blacks and Latinx have substantially higher risk of and time spent in working poverty than even their disadvantaged White counterparts. The racial/ethnic disparity holds even at the highest levels of education, with White men and women anticipating just one to 2 months in working poverty, Black women and men about 6 months and a year, respectively, and Latinx almost a year to 1.5 years, despite achieving higher educational attainment. Note, confidence intervals are especially wide for higher-educated Blacks and Latinx from economicallydisadvantaged backgrounds, a reflection of the rarity of that trajectory in the U.S. (Tilly 1998; Tomaskovic-Devey 2014).

Seen from another angle, from the perspective of educational attainment, disparities depend on race/ethnicity, gender, and early disadvantage. Having a high school diploma compared to less than high school/GED substantially reduces years spent in working poverty, halving (White men and women) or almost halving (Latinx and Blacks) WLE in working poverty for those who had higher early-SES (Table 2). A high school diploma does confer advantage to those who had lower early-SES, but not quite to the same degree.

In sum, over the period 2002-2012, we find evidence for some elements of Hypothesis 1. Those in vulnerable groups (Black, Latinx, and lower educated) experience both a higher risk of 
(Figure 2) and longer expectancies in (Figure 3) working poverty. Each of the predictors we consider - race/ethnicity, gender, early-SES, and educational attainment - is affected by positionality on the other predictors.

Table 2 about here

Vulnerable groups fared worse during the Great Recession

To test Hypothesis 2 that the Great Recession will differentially impact those in vulnerable groups, we examine expectancies in working poverty before and during the Great Recession ${ }^{8}$ for later-career workers, considering race/ethnicity, gender, early-life disadvantage, and educational attainment, and we focus on the difference between the recession and the pre-recession period. Results are shown in Figure 4 (bivariate) and in Table 2 (intersections). Estimates for the risk of working poverty are qualitatively similar, and they are reported in the appendix.

Figure 3 about here

Gender: The recession is associated with an increase in lifetime spent in working poverty for all groups (Table 2). The association between working poverty and the recession seems to have been roughly similar for women and men (Figure 3). In other words, the time spent in working poverty increased the same amount for women and men, with only minor differences (around 0.6 years). This seems to hold not only for the general population, but also for most group-comparisons, and it is contrary to previous findings regarding employment and unemployment which led to a consensus that men were affected more by the recession than women (e.g., Dudel and Myrskylä 2017).

\footnotetext{
${ }^{8}$ For brevity, we refer to "pre-recession" (2002-2007) to designate waves prior to the Great Recession and "recession" (2008-2012) for waves during and after the Great Recession, which in the U.S. was technically December 2007 through June 2009, according to the National Bureau of Economic Research.
} 
Race/ethnicity: All ethnic groups saw an increase in the time spent in working poverty since the market crash, and it was highest for both Latinos and Latinas. Confidence intervals for Black men and women include zero (Figure 3), which is likely partly driven by Blacks transitioning into unemployment or leaving the labor market (Appendix 1 Table 4). The more finely grained results shown in Table 2 indicate that racial/ethnic differences interact with educational attainment and early disadvantage; however, most group differences have too large confidence intervals to draw clear conclusions.

Early disadvantage: Point estimates for early-life SES are as hypothesized. Men and women who had more early-life disadvantages experienced approximately three months longer in working poverty in the Great Recession period than their more advantaged counterparts (e.g., high earlySES men: 6.1 months, 95\% CI: 4.0, 8.2; low-SES men: 8.9 months, 95\% CI 5.3, 12.7). In other words, the detrimental effect of the recession was stronger for those whose families of origin were more disadvantaged.

Educational attainment: Previous literature on the effect of the Great Recession found a strong educational gradient indicating that the lower educated were hit harder. The point estimates shown in Figure 3 suggest a similar pattern. The time spent in working poverty increased most for individuals without a high school degree (close to one additional year in working poverty). Generally, the recession is associated with an increase in working poverty for all educational levels and irrespective of gender.

Intersections: It is interesting to note that, in relative terms, working poverty increased more for lower-educated $(<\mathrm{HS} / \mathrm{GED})$ women $(+25.8,+21.9)$ than for lower-educated men $(+16.0,+1.1)$, while the opposite is true for the highly educated. This is similar for Whites and Blacks, but not for Latinx, though small samples make interpretation challenging. Nevertheless, results suggest how 
gender plays a role in the occupational selection mechanism, that is, stronger than race but not as strong as education. These findings reinforce, again, the importance of an intersectional approach.

Summary: Working poverty increased for all groups in the era of the Great Recession compared with the pre-Recession era. Results indicate some tendencies such as a slightly larger recessionary disadvantage for women than for men and for the lower educated. However, not all differences are substantial, and wide confidence intervals mean that the evidence for Hypothesis 2 is mixed.

Educational attainment as mediator

We study a relatively late part of the working life course, which is influenced by many factors. Early-life factors not only have direct effects on later working life, but also indirect effects by influencing the intervening factors on which labor market outcomes depend. An important example we consider here is educational attainment, and we provide a counterfactual exercise that allows us to compare what expectancies in working poverty would be if race/ethnicity did not directly influence educational attainment. Practically, if a policy intervention disassociated educational attainment from race/ethnicity, such that Blacks and Latinx were no longer disadvantaged compared to Whites, would there still be disparities in working poverty risk and expectancies?

The results of the counterfactual calculations are shown in Table 3 and can be understood as follows. The difference between White and Latino men in time spent in working poverty (20022012) is roughly 35.6 months. That is, Latinos spend eight times longer in working poverty (41 months for Latinos vs. 5 months for White men). Through the counterfactual, we assign Latinx and Black men and women the same distribution of educational attainment as their more advantaged White counterparts, while keeping early-life SES constant. In other words, even if there remained racial/ethnic disparities in early-life SES, what would be the racial/ethnic disparities in working 
poverty if a policy intervention was able to eliminate disparities in educational attainment. In this example, we find that the working poverty disparity between Latino and White men would persist, but be significantly reduced from 35.6 months to about 25.9 months.

Table 3 about here

In the counterfactual scenario, the differences between Whites and Latinx are strongly reduced, while the effect on the difference between Whites and Blacks is rather small (Table 3). The difference between White and Black men is only reduced by around 1.5 months. To understand the reason for this, it is important to consider that in this counterfactual exercise we, first, do not change early-life SES by race/ethnicity—Blacks still have a higher risk of a low early-life SES than Whites. Second, we do not change the returns to education by race/ethnicity, only the distribution of educational attainment—Blacks with a college degree still have a higher risk of working poverty than Whites with a college degree. The difference in the effect between Blacks and Latinx is likely due to a larger educational gradient in risk of working poverty for Latinx (Table 3). The difference between the lowest and the highest educational attainment in terms of the time spent in working poverty is three times as large for Latinx as for Blacks. This means that Latinx are "penalized" more for their low educational attainment than Blacks; conversely, they are rewarded more for their higher educational attainment than Blacks. From another perspective, it appears that Blacks' educational attainment is less predictive of their experiences of working poverty. It may also be that different experiences in early life with regard to disadvantage could be contributing to the difference in the mediation. In sum, these findings indicate that eliminating racial/ethnic disparities in educational attainment will only partially disrupt the link between race/ethnicity and working poverty if disparities in the returns to education remain. 


\section{Discussion}

Main findings

We have three main findings. First, life-course disadvantage is associated with increased later-life risk of and expectancies in working poverty. The disparity is dependent on race/ethnicity, gender, early-life disadvantage, education, and era. Latinx and Black women and men experience higher risk of working poverty than their White counterparts, regardless of early-life SES and educational attainment. The disparity by early-life disadvantage in risk of working poverty is much narrower for the higher educated, suggesting that higher education substantially mitigates early-life disadvantage.

In terms of expectancies, lower-educated Blacks and Latinx experience the longest expectancies in working poverty, with early-life disadvantaged Latinos spending almost one third (5.1 years out of 17.3 years) of their peak earning years in working poverty. Black women and Latinas experience almost 3.5 years out of their approximately 17-18 years of working life expectancy in working poverty. On the other hand, expectancy in working poverty for collegeeducated Whites, regardless of early-disadvantage, is almost invisible in Figure 3. Indeed, that expectancy in unemployment is higher than expectancy in working poverty (Appendix II Table 5) suggests that perhaps these higher-educated groups "choose" unemployment over low wages.

At the other end of the educational spectrum, it appears that lower-educated women and lower-educated Black and White men may register as not in the labor force (NILF) more so than their higher-educated counterparts. NILF is perhaps picking up withdrawal from the labor market (as well as disability) in addition to the retirement of more economically-stable individuals. This would suggest that, perhaps, unemployment or working poverty for these groups might be 
underestimated - the latter if retention wages are not high enough to promote labor force participation.

Second, we find strong evidence that risk of and expectancies in working poverty increased in the recessionary era. That increase fell disproportionately on certain subpopulations-lowereducated Blacks and Latinx and women more so than men. Black men and Latinx experienced the greatest increase in risk of working poverty in the recessionary era, with disadvantaged Latinos' risk climbing from $52.0 \%$ to $72.8 \%$. It is worth noting that Black men, who climb from $29.3 \%$ to 47.4\%, did not retain higher-paying jobs; they found themselves, instead, in states of unemployment (Appendix II Table 5). We find evidence that those who experienced more life-course disadvantages bore the brunt of the recession in terms of expectancies in working poverty. Black women and men, Latinx, and the lower educated experience the greatest increase in expectancies in working poverty. Within racial/ethnic groups, more early-life disadvantage appeared to more negatively impact women than men. Interestingly, whereas pre-recession educational attainment significantly mediated the association between early-life disadvantage and working poverty, in a period of macroeconomic crisis, early-life disadvantage appears to re-emerge as meaningful.

Third, educational attainment is an important mediator of the association between race/ethnicity and later-life working poverty. An intervention that disrupts the link between race/ethnicity and educational attainment substantially reduces the disparity in time spent in working poverty between Whites and Latinx, though less so for Blacks. This indicates that although policies directed at increasing educational attainment are important for poverty reduction, other factors linking race/ethnicity to later-life labor force participation and income must be addressed. 
Methodological considerations

Measuring poverty is not straightforward in any population, but is even more challenging for older Americans. The official poverty threshold's underestimation of poverty is particularly inaccurate at older ages. In 2010, the center year of our recessional analysis, the official poverty rate for those age 65 and older was 9\% (Danziger et al. 2012). However, the Supplemental Poverty Measure indicated this group's poverty rate was actually $15.9 \%$ in 2010 ; out-of-pocket medical costs are the primary driver of the almost seven percentage point discrepancy (Danziger et al. 2012). Also, although older Americans may escape above the federal poverty line more quickly, they tend to hover just above it (Jensen and McLaughlin 1997), with people aged 60-80 experiencing particularly high risk of poverty (Rank and Hirschl 2001). For these reasons, we can assume that the official poverty measure contributes to an underestimate of working poverty. There is no reason to expect that underestimate is systematically biased for the different subpopulations that we examine; however, it would be interesting to confirm this in future research by constructing the aforementioned supplemental poverty measure or a relative measure of poverty. Also relating to measurement, our measure of early-life SES is based on self-reported, retrospective information and on combining several variables (similar to Montez and Hayward 2014). However, we implemented several alternative approaches for combining the underlying variables - using a different threshold for the number of childhood adversities, and using factor analysis - and all sensitivity checks yield qualitatively similar results.

There are other potential limitations to our results. First, there are two key features related to our modeling approach. When interpreting our results, it is important to keep in mind that our estimates relate to what in demography is called a period perspective; that is, our results show how many years individuals would spent in working poverty if the conditions of the years 2002 to 2012 
would prevail throughout their late careers. This means that our findings do not necessarily represent the experience of the baby boomer cohorts or any other birth cohort (also see Dudel and Myrskylä 2020); they do, however, clearly show what the labor market conditions of the period under study imply with respect to disparities between groups. Also, the multistate approach we use rests on the Markov assumption. Essentially, this assumption implies that transition probabilities only depend on the current employment state and covariates, while previous employment states do not matter. The Markov assumption keeps our estimation problem tractable, in particular as we are interested in population-level quantities such as means and probabilities, and not in predicting individual trajectories. It is a useful simplification to estimate the former, but for the latter the Markov assumption likely is problematic.

Second, this study focuses on individual-level factors that sort people into different pathways. It is important to note that those pathways lead to different types of jobs (both occupation and fullversus part-time, etc.) and in different geographical spaces. Kearney and colleagues (2015) find that changes in occupational shares account for one-third of the decline in earnings for those with less than a high school degree. In other words, it is important to acknowledge the macroeconomic structure within which these individual-level factors operate. Likewise, of course, the Great Recession impacted regions of the U.S. differently, leading to large regional variation in negative labor market outcomes (Thiede and Monnat 2016). As our focus was on race/ethnicity, gender, early-life disadvantage, and education, we were unable to also take into consideration regional variation in risk of and expectancies in working poverty. However, it is an important area for future research.

Third, we interpret the difference in indicators between the pre-recession and the recession period as causal. Ideally this would require that no other factors than the financial crisis affected 
changes in outcomes over time. This is, obviously, not true. However, given the strong, sudden, and mostly unexpected effect of the recession, it does not seem unrealistic to assume that maybe not all, but most of the changes over time were caused by it.

\section{Conclusion}

This paper focuses on the risk of and expectancies in working poverty for later-career U.S. residents. This baby boomer cohort is of particular interest because of its size, but also because the Great Recession hit while most of the cohort was in later-career stage. This timing, along with occupational shifts from, for e.g., higher-paid more stable manufacturing and construction jobs to the lower-paid more precarious service economy, especially for those with lower educational attainment (Kearney et al. 2015), put the boomers at high risk of and longer expectancies in working poverty. As we would expect later-career workers to be at the peak of their earning potential, losing those years of higher earnings will affect them not only in the moment, but for their future Social Security earnings, pensions, and retirement savings. Working poverty is not only a problem of having less disposable income; it is also associated with poor health, likely driven by material (e.g., lack of health care, inability to retire) and non-material factors (insecurity of contingent work, psychosocial stressors) (Pförtner and Schmidt-Catran 2017).

In conclusion, our most vulnerable - older individuals who are Black or Latinx, who experienced early-life disadvantage, and those with lower-educational attainment - can expect to spend more of their peak earning years in working poverty, putting them at additional disadvantage in terms of other life outcomes, including their health. Achieving higher education only partially mediates the association between race/ethnicity and expectancies in later-life working poverty. These findings will only become increasingly important. In the last decade, pension reforms increased the age at retirement for younger cohorts of Americans; our results suggest that more 
years at work would translate into more years spent in working poverty for the most disadvantaged.

Finally, the COVID-19-inspired economic and health crises are likely to further exacerbate the disparities in and effects of working poverty. 


\section{Tables}

Table 1 Sample size and number of observations

\begin{tabular}{|c|c|c|c|c|c|}
\hline & Individuals & $\%$ & Transitions & $\%$ & $\begin{array}{l}\% \text { Transitions } \\
\text { from/to WP }\end{array}$ \\
\hline Total & 18,716 & 100.0 & 59,511 & 100.0 & 6.9 \\
\hline Men & 8,258 & 44.1 & 25,444 & 42.8 & 6.4 \\
\hline Women & 10,458 & 55.9 & 34,067 & 57.2 & 7.2 \\
\hline White & 12,245 & 65.4 & 41,140 & 69.1 & 3.1 \\
\hline Black & 3,958 & 21.1 & 11,170 & 18.8 & 12.9 \\
\hline Latinx & 2,513 & 13.4 & 7,201 & 12.1 & 19.4 \\
\hline$<$ High school/GED & 4,657 & 24.9 & 13,837 & 23.3 & 12.6 \\
\hline High school & 8,886 & 47.5 & 28,632 & 48.1 & 6.4 \\
\hline Some College & 1,132 & 6.0 & 3,487 & 5.9 & 5.8 \\
\hline College+ & 4,041 & 21.6 & 13,555 & 22.8 & 2.3 \\
\hline Low early-SES & 9,825 & 52.5 & 30,522 & 51.3 & 8.8 \\
\hline High early-SES & 8,891 & 47.5 & 28,989 & 48.7 & 4.8 \\
\hline
\end{tabular}


Table 2 Time spent in working poverty and effect of the recession by gender, ethnicity, educational attainment, and early-life SES

\begin{tabular}{|c|c|c|c|c|c|c|c|c|c|c|c|c|c|c|}
\hline \multirow{3}{*}{$\begin{array}{l}\text { Race/ } \\
\text { Ethnicity } \\
\text { White }\end{array}$} & \multirow{3}{*}{$\begin{array}{l}\text { Education } \\
\text { Total }\end{array}$} & \multicolumn{7}{|c|}{ Expectancy in working poverty (in years) } & \multicolumn{6}{|c|}{ Effect of the recession (difference in years) } \\
\hline & & \multirow{2}{*}{$\begin{array}{l}\text { Early } \\
\text { SES } \\
\text { - }\end{array}$} & \multirow{2}{*}{$\begin{array}{l}\text { Men } \\
0.43\end{array}$} & \multicolumn{2}{|c|}{$\begin{array}{c}95 \% \text { Confidence } \\
\text { interval }\end{array}$} & \multirow{2}{*}{$\begin{array}{r}\text { Women } \\
0.55\end{array}$} & \multicolumn{2}{|c|}{$\begin{array}{l}\text { 95\% Confidence } \\
\text { interval }\end{array}$} & \multirow{2}{*}{$\begin{array}{l}\text { Men } \\
0.17\end{array}$} & \multicolumn{2}{|c|}{$\begin{array}{l}95 \% \text { Confidence } \\
\text { interval }\end{array}$} & \multirow{2}{*}{$\begin{array}{r}\text { Women } \\
0.21\end{array}$} & \multicolumn{2}{|c|}{$\begin{array}{l}\text { 95\% Confidence } \\
\text { interval }\end{array}$} \\
\hline & & & & 0.36 & 0.51 & & 0.47 & 0.63 & & 0.05 & 0.30 & & 0.07 & 0.35 \\
\hline & \multirow{2}{*}{$<H S / G E D$} & High & 1.00 & 0.66 & 1.47 & 0.97 & 0.66 & 1.35 & 0.16 & -0.26 & 0.61 & 0.25 & -0.12 & 0.62 \\
\hline & & Low & 0.88 & 0.63 & 1.20 & 1.28 & 0.92 & 1.70 & 0.01 & -0.39 & 0.39 & 0.28 & -0.14 & 0.72 \\
\hline & \multirow{2}{*}{$H S$} & High & 0.46 & 0.34 & 0.61 & 0.46 & 0.36 & 0.57 & 0.18 & 0.04 & 0.36 & 0.15 & 0.02 & 0.32 \\
\hline & & Low & 0.53 & 0.40 & 0.72 & 0.67 & 0.52 & 0.82 & 0.15 & -0.06 & 0.38 & 0.21 & 0.02 & 0.42 \\
\hline & \multirow{2}{*}{$\begin{array}{l}\text { Some } \\
\text { college }\end{array}$} & High & 0.56 & 0.22 & 1.04 & 0.53 & 0.26 & 0.87 & 0.44 & 0.02 & 1.00 & 0.31 & -0.01 & 0.81 \\
\hline & & Low & 0.48 & 0.21 & 0.87 & 0.60 & 0.29 & 1.03 & 0.34 & -0.07 & 0.93 & 0.36 & -0.02 & 0.96 \\
\hline & \multirow{2}{*}{ College+ } & High & 0.14 & 0.07 & 0.23 & 0.19 & 0.11 & 0.29 & 0.11 & 0.03 & 0.26 & 0.13 & 0.04 & 0.27 \\
\hline & & Low & 0.19 & 0.10 & 0.31 & 0.30 & 0.17 & 0.46 & 0.14 & 0.02 & 0.37 & 0.23 & 0.05 & 0.48 \\
\hline \multirow[t]{9}{*}{ Black } & Total & - & 1.51 & 1.27 & 1.76 & 1.98 & 1.75 & 2.20 & 0.15 & -0.04 & 0.36 & 0.28 & 0.11 & 0.47 \\
\hline & \multirow{2}{*}{$<H S / G E D$} & High & 2.48 & 1.57 & 3.57 & 3.04 & 2.24 & 3.93 & 0.64 & -0.29 & 1.66 & 0.48 & -0.54 & 1.31 \\
\hline & & Low & 1.93 & 1.43 & 2.53 & 2.90 & 2.29 & 3.60 & 0.32 & -0.29 & 0.99 & 0.35 & -0.39 & 1.06 \\
\hline & \multirow{2}{*}{$H S$} & High & 1.44 & 1.02 & 1.98 & 2.16 & 1.72 & 2.64 & 0.71 & 0.21 & 1.28 & 0.41 & -0.17 & 0.93 \\
\hline & & Low & 1.33 & 1.00 & 1.70 & 2.17 & 1.83 & 2.54 & 0.52 & 0.09 & 1.00 & 0.37 & -0.15 & 0.85 \\
\hline & \multirow{2}{*}{$\begin{array}{l}\text { Some } \\
\text { college }\end{array}$} & High & 1.43 & 0.67 & 2.53 & 1.75 & 0.99 & 2.61 & 1.04 & 0.19 & 2.14 & 0.71 & -0.29 & 1.71 \\
\hline & & Low & 1.00 & 0.36 & 2.01 & 1.39 & 0.75 & 2.21 & 0.69 & 0.04 & 1.57 & 0.54 & -0.26 & 1.41 \\
\hline & \multirow{2}{*}{ College+ } & High & 0.97 & 0.49 & 1.59 & 0.57 & 0.30 & 0.97 & 0.93 & 0.38 & 1.60 & 0.33 & 0.05 & 0.72 \\
\hline & & Low & 1.02 & 0.49 & 1.73 & 0.62 & 0.32 & 1.03 & 0.92 & 0.29 & 1.73 & 0.36 & 0.06 & 0.79 \\
\hline \multirow[t]{9}{*}{ Latinx } & Total & - & 3.40 & 2.97 & 3.85 & 2.69 & 2.34 & 0.27 & 0.04 & 0.51 & 0.39 & 0.16 & 0.62 & 0.27 \\
\hline & \multirow{2}{*}{$<H S / G E D$} & High & 3.42 & 2.40 & 4.50 & 3.12 & 2.10 & 4.22 & 0.94 & -0.23 & 2.22 & 1.12 & 0.12 & 2.06 \\
\hline & & Low & 4.29 & 3.63 & 5.05 & 3.15 & 2.51 & 3.83 & 0.56 & -0.41 & 1.60 & 0.99 & 0.24 & 1.72 \\
\hline & \multirow{2}{*}{$H S$} & High & 1.88 & 1.21 & 2.71 & 1.92 & 1.24 & 2.58 & 1.01 & 0.27 & 1.84 & 0.64 & -0.01 & 1.30 \\
\hline & & Low & 3.04 & 2.30 & 3.88 & 2.15 & 1.64 & 2.71 & 1.17 & 0.19 & 2.16 & 0.70 & 0.07 & 1.34 \\
\hline & \multirow{2}{*}{$\begin{array}{l}\text { Some } \\
\text { college }\end{array}$} & High & 0.68 & 0.06 & 1.82 & 1.14 & 0.26 & 2.38 & 0.54 & 0.01 & 1.55 & 0.66 & -0.09 & 2.00 \\
\hline & & Low & 0.91 & 0.09 & 2.52 & 0.96 & 0.23 & 1.97 & 0.69 & 0.00 & 2.06 & 0.54 & -0.13 & 1.42 \\
\hline & \multirow{2}{*}{ College+ } & High & 0.79 & 0.30 & 1.51 & 1.08 & 0.42 & 1.95 & 0.71 & 0.18 & 1.52 & 0.77 & 0.16 & 1.62 \\
\hline & & Low & 1.55 & 0.69 & 2.67 & 1.39 & 0.52 & 2.70 & 1.23 & 0.32 & 2.41 & 1.02 & 0.23 & 2.26 \\
\hline
\end{tabular}


Table 3 Counterfactual calculations showing education as mediator linking race/ethnicity and working poverty, i.e., how the racial/ethnic disparity in working poverty would be narrowed if race/ethnicity did not predict educational attainment

\begin{tabular}{lllll} 
& \multicolumn{2}{c}{ Women } & \multicolumn{2}{c}{ Men } \\
\hline & $\begin{array}{l}\text { Months in } \\
\text { working } \\
\text { poverty }\end{array}$ & $\begin{array}{l}\text { Difference to } \\
\text { Whites }\end{array}$ & $\begin{array}{l}\text { Months in } \\
\text { working } \\
\text { poverty }\end{array}$ & $\begin{array}{l}\text { Difference to } \\
\text { Whites }\end{array}$ \\
\hline $\begin{array}{l}\text { Empirical } \\
\text { Black }\end{array}$ & 23.7 & 17.1 & 18.2 & 13.0 \\
$\quad$ Latinx & 32.3 & 25.7 & 40.8 & 35.6 \\
Counterfactual & & & & \\
$\quad$ Black & 23.5 & 16.9 & 16.2 & 11.5 \\
Latinx & 25.3 & 18.7 & 31.0 & 25.9
\end{tabular}




\section{Figures}

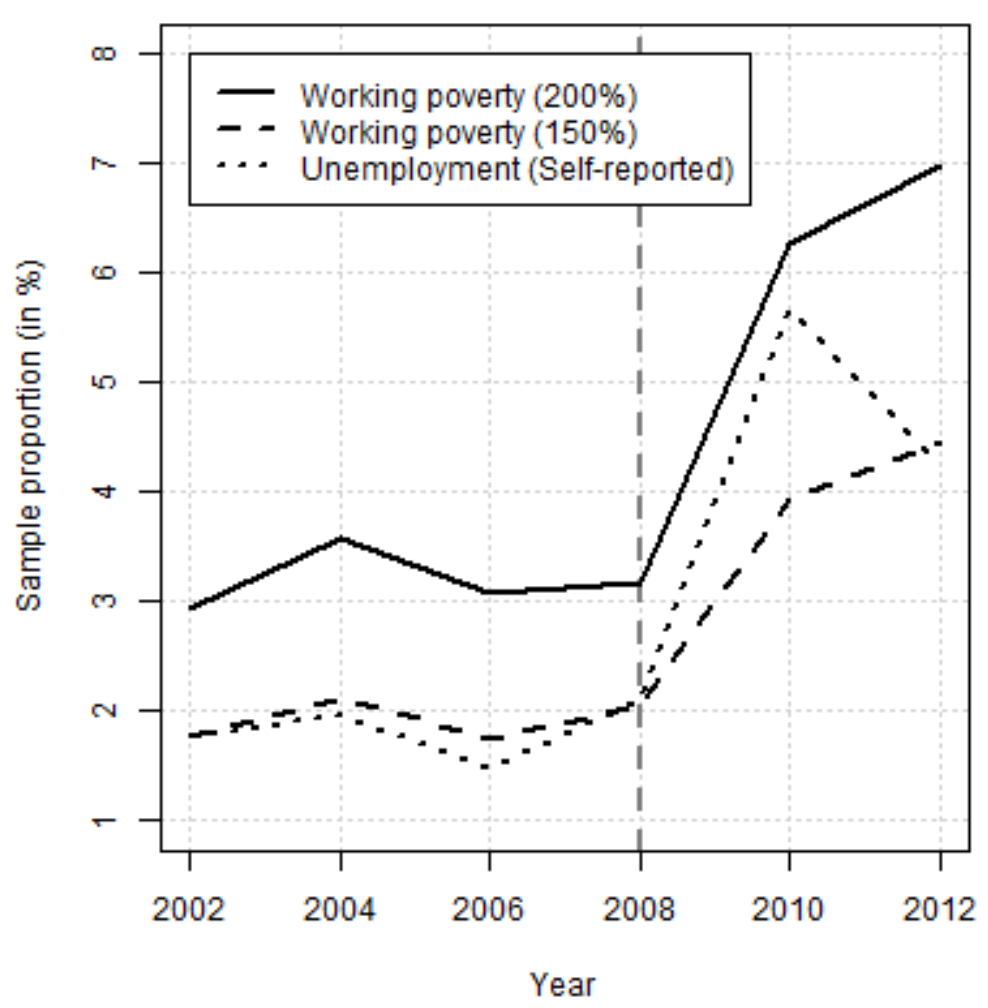

Fig. 1 Proportion of individuals in working poverty defined as $200 \%$ of poverty threshold (solid line), in working poverty using $150 \%$ of the poverty threshold (dashed line), proportion of individuals reporting unemployment (dotted line), and grey dashed line is onset of the effects of the recession 


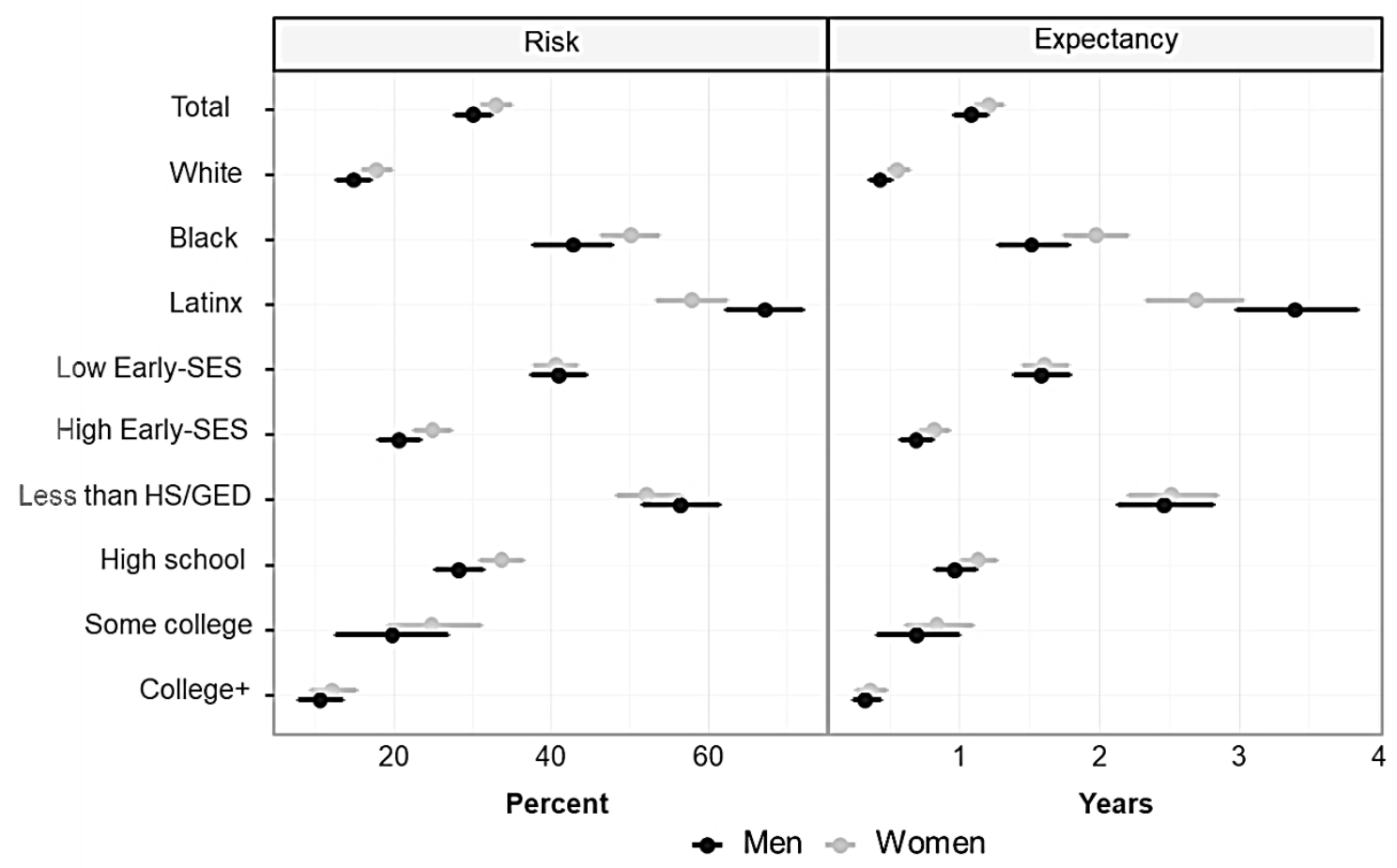

Fig. 2 Risk of (Panel A) and expectancies in (Panel B) working poverty by group (gender, race/ethnicity, education, early-life SES) 


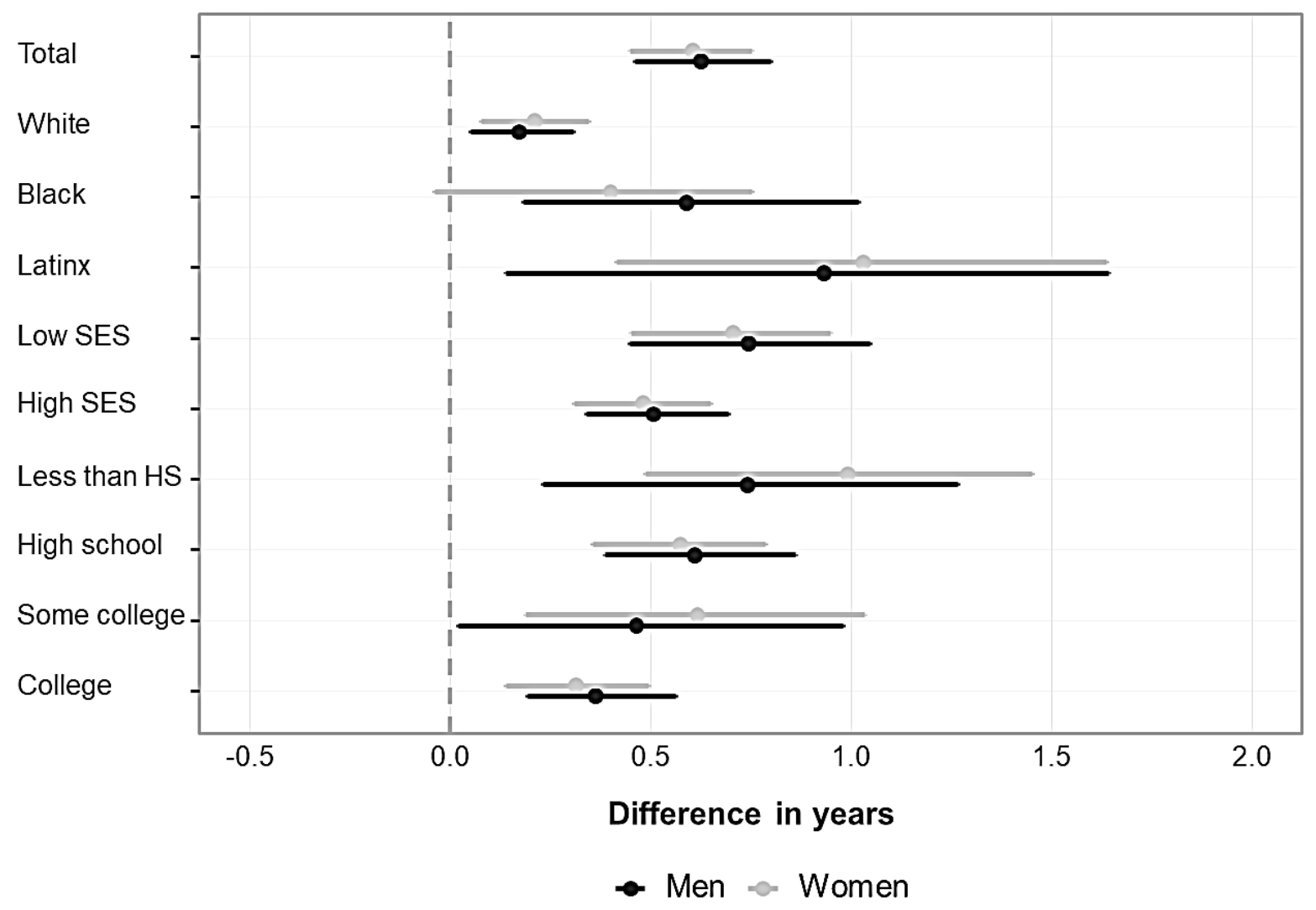

Fig. 3 Difference between lifetime spent in working poverty during the recession compared with prerecession 


\section{References}

Allison, P. D. (1982). Discrete-Time Methods for the Analysis of Event Histories. Sociological Methodology, 13(1982), 61-98.

Autor, D. H., Dorn, D., Autor, B. D. H., \& Dorn, D. (2013). The Growth of Low-Skill Service Jobs and the Polarization of the US Labor Market Citation Accessed Citable Link Detailed Terms The Growth of Low-Skill Service Jobs and the Polarization of the US Labor Market $\uparrow$. American Economic Review, 103(5), 1553-1597.

Bane, M. J., \& Ellwood, D. T. (1986). Slipping into and out of Poverty: The Dynamics of Spells. The Journal of Human Resources, 21(1), 1-23.

Becker, G. S., \& Tomes, N. (1994). Human Capital and the Rise and Fall of Families. In G. S. Becker (Ed.), Human Capital: A Theoretical and Empirical Analysis with Special Reference to Education (pp. 257-298). The University of Chicago Press.

Bernstein, S. F., Rehkopf, D., Tuljapurkar, S., \& Horvitz, C. C. (2018). Poverty dynamics, poverty thresholds and mortality: An age-stage Markovian model. PLoS ONE, 13(5), 1-21. doi:10.1371/journal.pone.0195734

Blau, P. M., \& Duncan, O. D. (1967). The American occupational structure.

Bloome, D. (2014). Racial Inequality Trends and the Intergenerational Persistence of Income and Family Structure. American Sociological Review, 79(6), 1196-1225. doi: $10.1177 / 0003122414554947$

Brady, D. (2003). Rethinking the Sociological Measurement of Poverty. Social Forces, 81(3), 715751. doi:10.1353/sof.2003.0025

Brady, D., Finnigan, R. M., \& Hubgen, S. (2017). Rethinking the Risks of Poverty: A Framework for Analyzing Prevalences and Penalties. American Journal of Sociology, 123(3), 740-786. 
doi: $10.1086 / 693678$

Brady, D., Fullerton, A. S., \& Cross, J. M. (2010). More than just nickels and dimes: a crossnational analysis of working poverty in affluent democracies. Social problems, 57(4), 559585. doi:10.1525/sp.2010.57.4.559

Browne, I., \& Misra, J. (2003). The Intersection of Gender and Race in the Labor Market. Annual Review of Sociology, 29, 487-513. doi:10.1146/annurev.soc.29.010202.100016

Cahill, K. E., Giandrea, M. D., \& Quinn, J. F. (2015). Retirement patterns and the macroeconomy, 1992-2010: The prevalence and determinants of bridge jobs, phased retirement, and reentry among three recent cohorts of older Americans. Gerontologist, 55(3), 384-403. doi:10.1093/geront/gnt146

Calvo, E., Madero-Cabib, I., \& Staudinger, U. M. (2017). Retirement sequences of older Americans: Moderately destandardized and highly stratified across gender, class, and race. The Gerontologist, 58(6), 1166-1176.

Cameron, A. C., \& Trivedi, P. K. (2005). Microeconometrics: methods and applications. Cambridge university press.

Cellini, S. R., McKernan, S.-M., \& Ratcliffe, C. (2008). The Dynamics of Poverty in the United States: A Review of Data, Methods, and Findings. Journal of policy analysis and management, 27(3), 577-605. doi:10.1002/pam

Cho, S., Crenshaw, K. W., \& Mccall, L. (2013). Toward a Field of Intersectionality Studies: Theory, Applications, and Praxis. Signs: Journal of Women in Culture and Society, 38(4), 785-810.

Collins, P. H. (2015). Intersectionality's Definitional Dilemmas. Annual Review of Sociology, 41, 1-20. doi:10.1146/annurev-soc-073014-112142

Conley, D. (1999). Being black, living in the red: Race, wealth, and social policy in America. Univ 
of California Press.

Crenshaw, K. W. (1994). Mapping the margins: Intersectionality, Identity Politics, and Violence Against Women of Color. In M. A. Fineman \& R. Mykitiuk (Eds.), The Public Nature of Private Violence (pp. 93-118). New York: Routledge.

Danziger, S., Chavez, K., \& Cumberworth, E. (2012). Poverty and the Great Recession. A Great Recession Brief, (October), 1-6.

Desmond, M., \& Gershenson, C. (2016). Housing and employment insecurity among the working poor. Social Problems, 63(1), 46-67. doi:10.1093/socpro/spv025

Desmond, M., \& Western, B. (2018). Poverty in America: New Directions and Debates. Annual Review of Sociology, 44, 305-318. doi:10.1146/annurev-soc-060116

Dewilde, C. (2003). A Life-Course Perspective on Social Exclusion and Poverty. British Journal of Sociology, 54(1), 109-128. doi:10.1080/0007131032000045923

DiPrete, T. A. (2002). Life Course Risks, Mobility Regimes, and Mobility Consequences: A Comparison of Sweden, Germany, and the United States. American Journal of Sociology, 108(2), 267-309. doi:10.1086/344811

DiPrete, T. A., \& Eirich, G. M. (2006). Cumulative advantage as a mechanism for inequality: A review of theoretical and empirical developments. Annual Review of Sociology, 32(2006), 271-297. doi:10.1146/annurev.soc.32.061604.123127

Dudel, C., \& Myrskylä, M. (2017). Working Life Expectancy at Age 50 in the United States and the Impact of the Great Recession. Demography, 54(6), 2101-2123. doi:10.1007/s13524-0170619-6

Dudel, C., \& Myrskylä, M. (2020). Cohort Trends in Working Life Expectancies at Age 50 in the United States: A Register-Based Study Using Social Security Administration Data. The 
Journals of Gerontology: Series B, 1-11. doi:10.1093/geronb/gbaa015

Elder Jr., G. H. (1998). The life course as developmental theory. Child Development, 69(1), 1-12. doi: $10.2307 / 1132065$

Engemann, K. M., \& Wall, H. J. (2009). The effects of recessions across demographic groups. Federal Reserve Bank of St. Louis (Vol. 92).

Farber, H. S. (2008). Employment Insecurity: The Decline in Worker-Firm Attachment in the United States. CEPS Working Paper.

Farber, H. S. (2010). Job loss and the decline in job security in the United States. Labor in the new economy.

Farber, H. S. (2011). Job loss in the Great Recession: Historical perspective from the displaced workers survey, 1984-2010. Nber Working Paper.

Finnigan, R., \& Hale, J. M. (2018). Working 9 to 5? Union Membership and Work Hours and Schedules. Social Forces, 49, 1-27. doi:10.1093/sf/sox101

Fontenot, K., Semega, J., \& Kollar, M. (2018). U.S. Census Bureau, Current Population Reports, P60-263. In Income and and Poverty Poverty the United States : 2017. Washington, D.C.: U.S. Government Printing Office.

Gran, J. M., Lie, S. A., Øyeflaten, I., Borgan, Ø., \& Aalen, O. O. (2015). Causal inference in multistate models-sickness absence and work for 1145 participants after work rehabilitation. $B M C$ public health, 15(1), 1082.

Halpin, B. W. (2015). Subject to Change Without Notice: Mock Schedules and Flexible Employment in the United States. Social Problems, 62(3), 419-438. doi:10.1093/socpro/spv008

Hayward, M. D., Hardy, M. A., \& Liu, M.-C. (1994). Work after retirement: The experiences of 
older men in the United States. Social Science Research, 23(1), 82-107.

Hayward, M. D., \& Lichter, D. T. (1998). A Life Cycle Model of Labor Force Inequality. Sociological Methods \& Research.

Hoem, J. M. (1977). A Markov chain model of working life tables. Scandinavian Actuarial Journal, 1977(1), 1-20. doi:10.1080/03461238.1977.10405621

Hout, M., \& DiPrete, T. A. (2006). What we have learned: RC28's contributions to knowledge about social stratification. Research in Social Stratification and Mobility, 24(1), 1-20. doi:10.1016/j.rssm.2005.10.001

Hoynes, H. W., Page, M. E., \& Stevens, A. H. (2006). Poverty in America: Trends and explanations. The Journal of Economic Perspectives, 20(1), 47-68.

Jargowsky, P. A. (1997). Poverty and place: Ghettos, barrios, and the American city. Russell Sage Foundation.

Jensen, L., \& McLaughlin, D. K. (1997). The Escape from poverty among rural and urban elders. The Gerontologist, 37(4), 462-468.

Julius, W. W. (1987). The truly disadvantaged: The inner city, the underclass, and public policy. Chicago: The University of Chicago.

Kalleberg, A. L., Reskin, B. F., \& Hudson, K. E. N. (2000). Bad Jobs in America : Standard and Nonstandard Employment Relations and Job Quality in the United States. American Sociological Review, 65(2), 256-278.

Kearney, M. S., Hershbein, B., \& Jácome, E. (2015). Profiles of change: Employment, earnings, and occupations from 1990-2013.

Keys, B. J., \& Danziger, S. H. (2008). Hurt the Worst: The Rise of Unemployment among Disadvantaged and Advantaged Male Workers, 1968-2003. In K. S. Newman (Ed.), Laid off, 
laid low: Political and economic consequences of employment insecurity (pp. 56-73). New York: Columbia University Press.

Killewald, A., \& Bryan, B. (2018). Falling Behind: The Role of Inter- and Intragenerational Processes in Widening Racial and Ethnic Wealth Gaps through Early and Middle Adulthood. Social Forces, 97(December), 705-740. doi:10.1093/sf/soy060

Lariscy, J. T., Hummer, R. A., \& Hayward, M. D. (2015). Hispanic older adult mortality in the United States: New estimates and an assessment of factors shaping the Hispanic paradox. Demography, 52(1), 1-14. doi:10.1038/jid.2014.371

Lariscy, J. T., Nau, C., Firebaugh, G., \& Hummer, R. A. (2016). Hispanic-White Differences in Lifespan Variability in the United States. Demography, 53(1), 215-239. doi:10.1007/s13524015-0450-x

Lee, Y. G., Teng, H.-M., Lim, S.-H., \& Gallo, W. T. (2005). Older Workers: Who are the working poor in the U.S.? Hallym Int $J$ Aging, 7(2), 95-113. doi:10.1016/j.pestbp.2011.02.012.Investigations

Li, A., Wallace, M., \& Hyde, A. (2019). Degrees of inequality: The Great Recession and the college earnings premium in U.S. metropolitan areas. Social Science Research, 84(August), 102342. doi:10.1016/j.ssresearch.2019.102342

Lichter, D. T., \& Crowley, M. L. (2002). Poverty in America: Beyond Welfare Reform. Population Bulletin, 57(2).

Lorenti, A., Dudel, C., Hale, J. M., \& Myrskylä, M. (2020). Working and disability expectancies at old ages: the role of childhood circumstances and education. MPIDR Working Paper, 1-37. doi:10.4054/MPIDR-WP-2020-006

Lorenti, A., Dudel, C., \& Myrskylä, M. (2019). The Legacy of the Great Recession in Italy: A 
Wider Geographical, Gender, and Generational Gap in Working Life Expectancy. Social Indicators Research, 142(1), 283-303. doi:10.1007/s11205-018-1910-7

Magnuson, K., \& Votruba-Drzal, E. (2009). Enduring influences of childhood poverty. Focus, 26(2), 32-37.

Mayer, K. U. (2009). New directions in life course research. Annual Review of Sociology, 35(1), 413-433. doi:10.1146/annurev.soc.34.040507.134619

McKernan, S. M., \& Ratcliffe, C. (2005). Events that trigger poverty entries and exits. Social Science Quarterly, 86(SPEC. ISS.), 1146-1169. doi:10.1111/j.0038-4941.2005.00340.x

Meara, E. R., Richards, S., \& Cutler, D. M. (2008). The gap gets bigger: changes in mortality and life expectancy, by education, 1981-2000. Health Affairs, 27(2), 350-360.

Meyer, B. D., \& Sullivan, J. X. (2012). Identifying the Disadvantaged: Official Poverty, Consumption Poverty, and the New Supplemental Poverty Measure. Journal of Economic Perspectives, 26(3), 111-136.

Montez, J. K., \& Hayward, M. D. (2014). Cumulative Childhood Adversity, Educational Attainment, and Active Life Expectancy Among U.S. Adults. Demography, 51(2), 413-435. doi:10.1007/s13524-013-0261-x

Nandi, A., Glymour, M. M., Kawachi, I., \& VanderWeele, T. J. (2012). Using Marginal Structural Models to Estimate the Direct Effect of Adverse Childhood Social Conditions on Onset of Heart Disease, Diabetes, and Stroke. Epidemiology, 23(2), 223-232. doi:10.1097/EDE.0b013e31824570bd.Using

Neckerman, K. M., \& Torche, F. (2007). Inequality: Causes Consequences. Annual Review of Sociology, 33, 335-357.

Pförtner, T.-K. K., \& Schmidt-Catran, A. W. (2017). In-work poverty and self-rated health in a 
cohort of working Germans: A hybrid approach for decomposing within-person and betweenpersons estimates of in-work poverty status. American Journal of Epidemiology, 185(4), 274282. doi:10.1093/aje/kww218

Pilkauskas, N., \& Michelmore, K. (2019). The Effect of the Earned Income Tax Credit on Housing and Living Arrangements. Demography, 56(4), 1303-1326. doi:10.1007/s13524-019-007915

Pleau, R., \& Shauman, K. (2013). Trends and correlates of post-retirement employment, 19772009. Human Relations, 66(1), 113-141.

RAND Center for the Study of Aging. (2017). RAND HRS Data, Version P. Santa Monica, CA.

Rank, M. R., \& Hirschl, T. A. (2001). The Occurrence of Poverty across the Life Cycle: Evidence from the PSID. Journal of Policy Analysis and Management, 20(4), 737-755.

Rehkopf, D. H., Adler, N. E., \& Rowe, J. W. (2017). The impact of health and education on future labour force participation among individuals aged 55-74 in the United States of America: The MacArthur Foundation Research Network on an Aging Society. Ageing and Society, 37(7), 1313-1337. doi:10.1017/S0144686X16000295

Riosmena, F., Kuhn, R., \& Jochem, W. C. (2017). Explaining the Immigrant Health Advantage: Self-selection and Protection in Health-Related Factors Among Five Major National-Origin Immigrant Groups in the United States. Demography, 54(1), 175-200. doi:10.1007/s13524016-0542-2

Schafer, M. H., Ferraro, K. F., \& Mustillo, S. A. (2011). Children of misfortune: early adversity and cumulative inequality in perceived life trajectories. American Journal of Sociology, 116(4), 1053-1091. doi:10.1086/655760

Schafer, M. H., Wilkinson, L. R., \& Ferraro, K. F. (2013). Childhood (Mis)fortune, educational 
attainment, and adult health: Contingent benefits of a college degree? Social Forces, 91(3), 1007-1034. doi:10.1093/sf/sos192

Sewell, W. H., Haller, A., \& Ohlendorf, G. W. (1970). The Educational and Early Occupational Status Attainment Process: Replication and Revision. American Sociological Review, 35(6), $1014-1027$.

Skoog, G. R., \& Ciecka, J. E. (2010). Measuring years of inactivity, years in retirement, time to retirement, and age at retirement within the markov model. Demography, 47(3), 609-628.

Stevens, A. H. (1994). American Economic Association The Dynamics of Poverty Spells: Updating Bane and Ellwood. American Economic Review, 84(2).

Stevens, A. H. (2012). Chapter 15 Poverty Transitions. In The Oxford handbook of the economics of poverty (pp. 735-771).

Struffolino, E., \& Van Winkle, Z. (2019). Is there only one way out of in-work poverty? Difference by gender and race in the US. WZB Discussion Paper, SP I 2019-(January).

Thiede, B. C., \& Kim, H. (2015). Changing Patterns of Work and Poverty During and After the Great Recession. The 2015 Department of Labor Scholars Program, 1-44.

Thiede, B. C., Lichter, D. T., \& Sanders, S. R. (2015). America's Working Poor: Conceptualization, Measurement, and New Estimates. Work and Occupations, 42(3), 267-312. doi:10.1177/0730888415573635

Thiede, B. C., Lichter, D. T., \& Slack, T. (2018). Working, but poor: The good life in rural America? Journal of Rural Studies, 59, 183-193. doi:10.1016/j.jrurstud.2016.02.007

Thiede, B. C., \& Monnat, S. (2016). The Great Recession and America's geography of unemployment. Demographic Research, 35(September), 891-928. doi:10.4054/DemRes.2016.35.30 
Tilly, C. (1998). Durable inequality. Univ of California Press.

Tomaskovic-Devey, D. (2014). The Relational Generation of Workplace Inequalities. Social Currents, 1, 51-73. doi:10.1177/2329496513514032

Toossi, M. (2002). A century of change: the U.S. labor force, 1950-2050. Monthly Labor Review, 15-28. doi:10.2307/3487659

University of Michigan. (2017). Health and Retirement Study Public Use Dataset. Ann Arbor, MI.

Van Winkle, Z., \& Struffolino, E. (2018). When working isn't enough: Family demographic processes and in-work poverty across the life course in the United States. Demographic Research, 39(September), 365-380. doi:10.4054/DemRes.2018.39.12

VanderWeele, T. J. (2015). Explanation in causal inference: methods for mediation and interaction. Oxford University Press.

VanderWeele, T. J., \& Robinson, W. R. (2015). Confounding and Mediating Variables, 25(4), 473484. doi:10.1097/EDE.0000000000000105.On

Warner, D. F., Hayward, M. D., \& Hardy, M. A. (2010). The Retirement Life Course in America at the Dawn of the Twenty-First Century. Population Research and Policy Review, 29(6), 893919.

Western, B., Bloome, D., Sosnaud, B., \& Tach, L. (2012). Economic Insecurity and Social Stratification. Annual Review of Sociology, 38, 341-359. doi:10.1146/annurev-soc-071811145434

Yee, T. W. (2010). The VGAM package for categorical data analysis. Journal of Statistical Software, 32(10), 1-34. 


\section{Appendix I}

Table 4 Expectancies in different employment states by gender, race/ethnicity, early-life SES, and educational attainment

All men:
White
Black
Latino
Lower Early-SES
Higher Early-SES
Less than HS
HS/GED
Some college
College+

All women:

White

Black

Latina

Lower Early-SES

Higher Early-SES

Less than HS

HS/GED

Some college

College+

Full/part
time
8.67
9.78
6.40
6.95
7.55
9.56
5.30
8.42
9.32
11.53

7.05

8.19

5.55

4.73

5.95

8.12

3.66

7.19

8.29

9.31

\begin{tabular}{|c|}
\hline $\begin{array}{r}\text { Working } \\
\text { poor }\end{array}$ \\
\hline 1.08 \\
\hline 0.43 \\
\hline 1.51 \\
\hline 3.40 \\
\hline 1.59 \\
\hline 0.69 \\
\hline 2.46 \\
\hline 0.96 \\
\hline 0.69 \\
\hline 0.32 \\
\hline
\end{tabular}

0.43

3.40

1.59

0.69

2.46

0.96

0.69

0.32

1.20

0.55

1.98

2.69

1.61

0.81

2.52

1.13

0.83

0.36 Unemployed

0.66

0.53

0.82

1.01

0.70

0.62

0.88

0.60

0.80

0.56

0.53

0.46

0.66

0.60

0.54

0.51

0.52

0.57

0.53

0.43

$\begin{array}{rr}\begin{array}{r}\text { Not in labor } \\ \text { force }\end{array} & \text { Partial LE } \\ 6.90 & 17.60 \\ 6.74 & 17.63 \\ 7.82 & 16.98 \\ 6.23 & 18.26 \\ 7.26 & 17.50 \\ 6.61 & 17.68 \\ 7.74 & 16.94 \\ 7.30 & 17.56 \\ 6.66 & 17.67 \\ 5.65 & 18.17\end{array}$

9.16

18.27

8.92

9.23

10.02

9.71

8.63

10.67

9.14

8.19

8.27
18.30

17.92

18.61

18.21

18.33

17.88

18.37

18.09

18.49 


\section{Appendix II}

Table 5 The effect of the Great Recession for risk of working poverty and expectancies in different employment states by gender, race/ethnicity, early-life SES, and educational attainment

\begin{tabular}{|c|c|c|c|c|c|}
\hline & Risk & $\begin{array}{r}\text { Full/part } \\
\text { time }\end{array}$ & $\begin{array}{r}\text { Working } \\
\text { poor }\end{array}$ & Unemployed & $\begin{array}{r}\text { Not in labor } \\
\text { force }\end{array}$ \\
\hline All men: & 0.13 & -1.30 & 0.62 & 0.44 & 0.19 \\
\hline White & 0.05 & -0.53 & 0.17 & 0.29 & 0.04 \\
\hline Black & 0.10 & -1.83 & 0.59 & 0.53 & 0.53 \\
\hline $\begin{array}{l}\text { Latino } \\
\text { Lower Early- }\end{array}$ & 0.12 & -1.24 & 0.93 & 0.78 & 0.00 \\
\hline $\begin{array}{l}\text { SES } \\
\text { Higher Early- }\end{array}$ & 0.14 & -1.84 & 0.74 & 0.55 & 0.38 \\
\hline SES & 0.12 & -0.80 & 0.51 & 0.34 & 0.01 \\
\hline Less than HS & 0.11 & -2.45 & 0.74 & 0.74 & 0.51 \\
\hline HS/GED & 0.13 & -1.39 & 0.61 & 0.41 & 0.41 \\
\hline Some college & 0.09 & -0.08 & 0.46 & 0.58 & -0.80 \\
\hline College + & 0.09 & 0.07 & 0.36 & 0.19 & -0.52 \\
\hline All women: & 0.11 & -0.93 & 0.61 & 0.35 & -0.07 \\
\hline White & 0.05 & -0.58 & 0.21 & 0.34 & -0.08 \\
\hline Black & 0.04 & -0.82 & 0.40 & 0.34 & 0.20 \\
\hline $\begin{array}{l}\text { Latina } \\
\text { Lower Early- }\end{array}$ & 0.11 & 0.32 & 1.03 & 0.25 & -1.31 \\
\hline $\begin{array}{l}\text { SES } \\
\text { Higher Early- }\end{array}$ & 0.10 & -1.31 & 0.71 & 0.31 & 0.26 \\
\hline SES & 0.11 & -0.48 & 0.48 & 0.39 & -0.48 \\
\hline Less than HS & 0.09 & -0.86 & 0.99 & 0.28 & -0.29 \\
\hline HS/GED & 0.12 & -1.26 & 0.58 & 0.41 & 0.15 \\
\hline Some college & 0.14 & -1.06 & 0.62 & 0.39 & -0.17 \\
\hline College+ & 0.08 & -0.13 & 0.31 & 0.25 & -0.55 \\
\hline
\end{tabular}


